\title{
Topographic Facial Nerve Transplantation
}

\author{
Benedikt M. Schwaiger, MD; Ines Tinhofer, MD²; Johannes Steinbacher, MD²; Thomas Rath, MD; \\ Guenther Meissl, MD; Chieh-Han John Tzou, MD, PhD²,4, \\ 'Department of Cardiac Surgery, München Klinik Bogenhausen, Munich, Germany \\ 2Plastic and Reconstructive Surgery, Department of Surgery, Hospital of Divine Savior, Vienna, Austria \\ ${ }^{3}$ Division of Plastic and Reconstructive Surgery, Department of Surgery, Medical University of Vienna, Austria \\ ${ }^{4}$ Faculty of Medicine, Sigmund Freud University, Vienna, Austria \\ ${ }^{5}$ Tzou Medical. Vienna, Austria
}

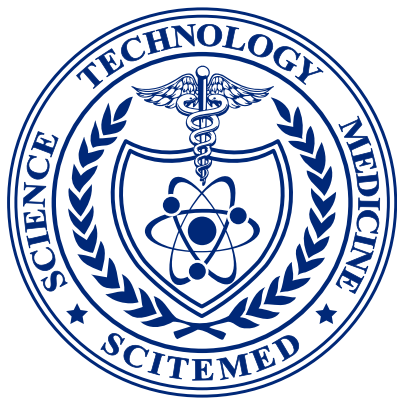

\begin{abstract}
This case report describes our successfully attempt to perform a topographically correct sural nerve transplantation in the extracranial facial nerve stem using the intraneural facial nerve stem topography proposed by Meissl in 1979. This is the first reported case of successful fascicular nerve grafting of the facial nerve stem following extensive laceration. The surgery was performed on a young male patient who had suffered total left facial paralysis after a traumatic car accident with laceration of the facial nerve. During a second look surgery, proximal and distal facial nerve stumps with significant nerve gaps were identified. Using Meissl's approach, the nerve gaps were bridged with five sural nerve grafts. Follow-up after 48 months showed satisfactory results with only minimal synkinesis, thus avoiding additional procedures. No additional corrective interventions were therefore required.
\end{abstract}

\section{CLINICAL REPORT}

\section{Presentation}

This is a clinical report describing the case of performing a topographically correct sural nerve transplantation in the extracranial facial nerve stem using the intraneural facial nerve stem topography. Proposed by Meissl in 1979, this is the first case of successful fascicular nerve grafting of the facial nerve stem following extensive laceration. It was performed on a young male patient who had suffered a deep traumatic soft tissue laceration to the left preauricular area because of a high velocity car accident. In the surgery performed immediately upon presentation, the facial nerve stump could not be identified at the stylomastoid foramen and was therefore not reconstructed. Subsequently, he suffered complete total left facial nerve paralysis.

Three days after the initial presentation, when the swelling of the trauma area had subsided, a high resolution ultrasound was conducted and the transected facial nerve stump was located at the stylomastoid foramen, confirming the indication of secondary facial nerve reconstruction. Surgical exploration identified the distal facial nerve stumps within the parotid gland. There was a significant gap between the nerve stumps due to trauma mechanism. A tension-free direct nerve repair could not be deduced since the gap extended from the extracranial nerve stem to the pes anserinus of the facial nerve within the parotid gland.

\section{Management}

Attempting to reconstruct the facial nerve after more than 72 hours post trauma requires the knowledge of the facial nerve's intraneural topography. The senior author referred to an article by Meissl published in 1979 in an Austrian publication in which the intraneural topography of the extracranial facial nerve stem had been examined [1]. Meissl had paired the electrophysiological examination of the facial nerve stem of cats in vivo with sequential microscopic analyses of human cadaveric nerves. He had found three areas within the horizontal cross-section of the proximal facial nerve stem: (i) the ventro-medial portion innervating the muscles of the forehead and upper eyelid, (ii) the lateral portion innervating the lower eyelid and cheek, and upper lip, and (iii) the dorsal fascicles supplying the muscles of the neck and lower lip (Figure 1). We

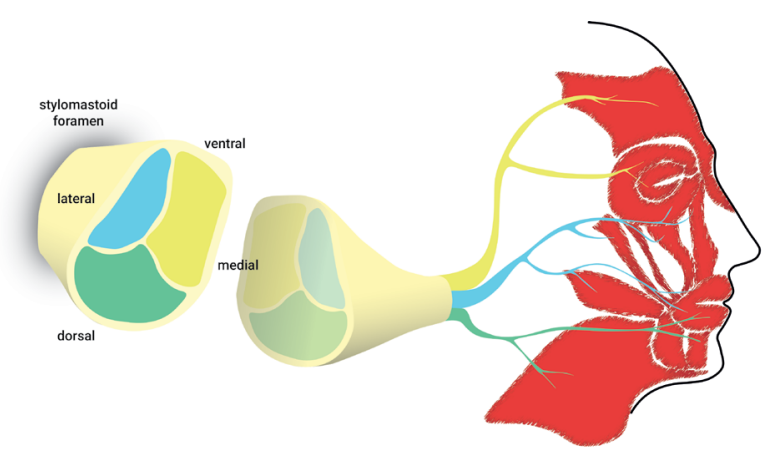

Figure 1. Schematic illustration of the fascicular topography of the facial nerve at the stylomastoid foramen and the corresponding innervation of facial muscles as described in the 1979 paper by Meissl.

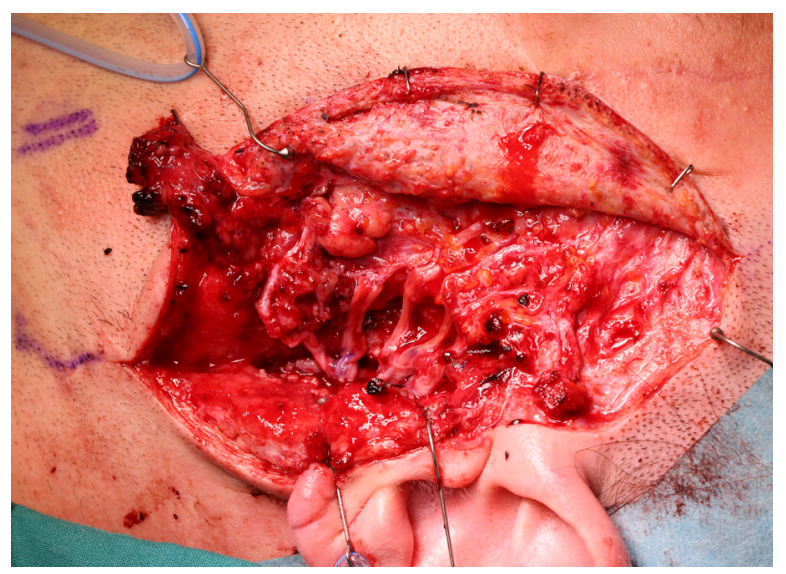

Figure 2. Intraoperative view of the fascicular left facial nerve reconstruction using five sural nerve grafts. 


\begin{tabular}{|c|c|c|c|c|}
\hline Examination & Voluntary movement & Resting symmetry & Synkinesis & Composite score \\
\hline Preoperative & 20 & 20 & 0 & 0 \\
\hline 8 months follow-up & 52 & 10 & 0 & 42 \\
\hline 48 months follow-up & 76 & 5 & 1 & 70 \\
\hline
\end{tabular}

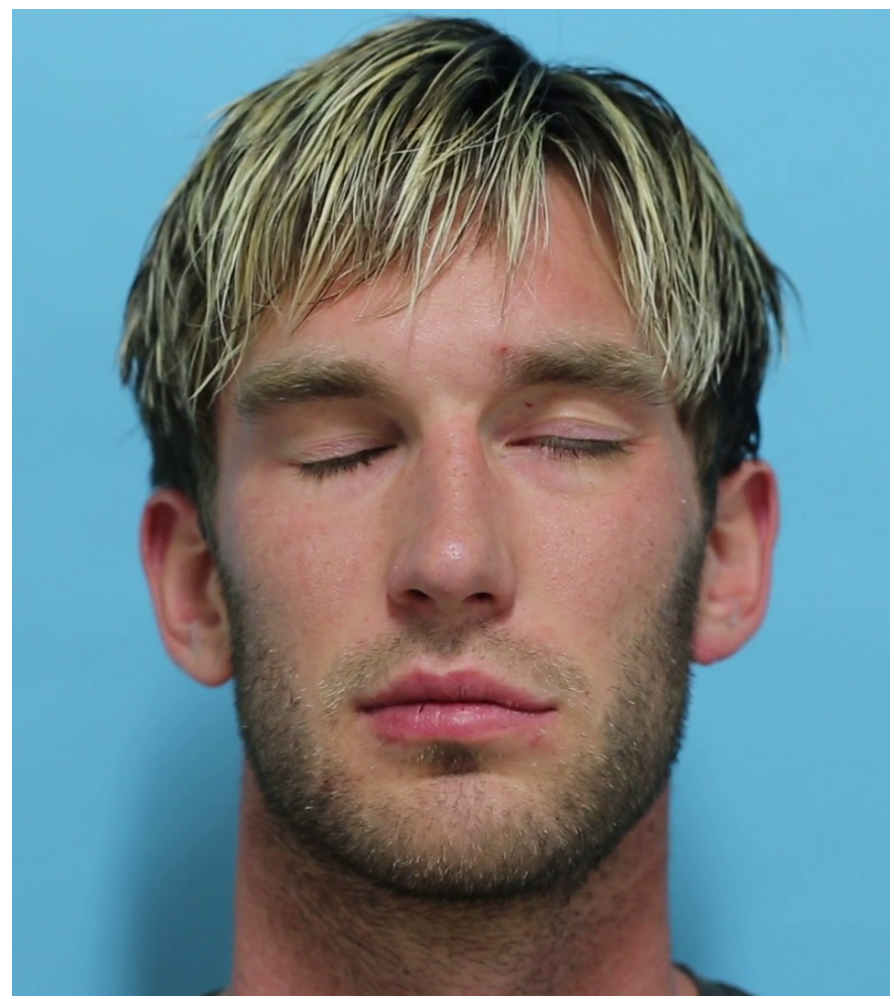

Figure 3. Closing of the eyelids 48 months after reconstructive surgery. Note the marked reduction in lagophthalmos of the left eye and resting asymmetry of the mid- and lower face.

expected to identify the nerve stumps in a second-look surgery which would allow ipsilateral repair instead of a cross-face nerve graft, which would be the alternate option in case of failure to repair the transected facial nerve.

We performed a fascicular repair of the proximal facial nerve stump at the stylomastoid foramen using five autologous grafts from the sural nerve of approximately $6 \mathrm{~cm}$ length (Figure 2). They were arranged according to the topography proposed by Meissl for the restoration of distal continuity of the facial nerve.

\section{Outcome}

Follow-ups were conducted after eight months and four years post trauma. Both showed excellent clinical outcomes with good symmetric mimic muscle contractions and minimalsynkinesias (Figure 3, Figure 4, Video 1: https://youtu. be/doppARxcr5k). The Sunnybrook Facial Grading System [2] scores at the initial presentation and at the time of follow-up after eight and 48 months are summarized in Table 1. The patient was satisfied with the result and there was no need for further corrective interventions. In this way, additional procedures like nerve or muscle grafting, as well as myectomy or botulinum toxin injection were avoided.

\section{DISCUSSION}

Direct tension-free nerve coaptation is generally preferred in nerve repair

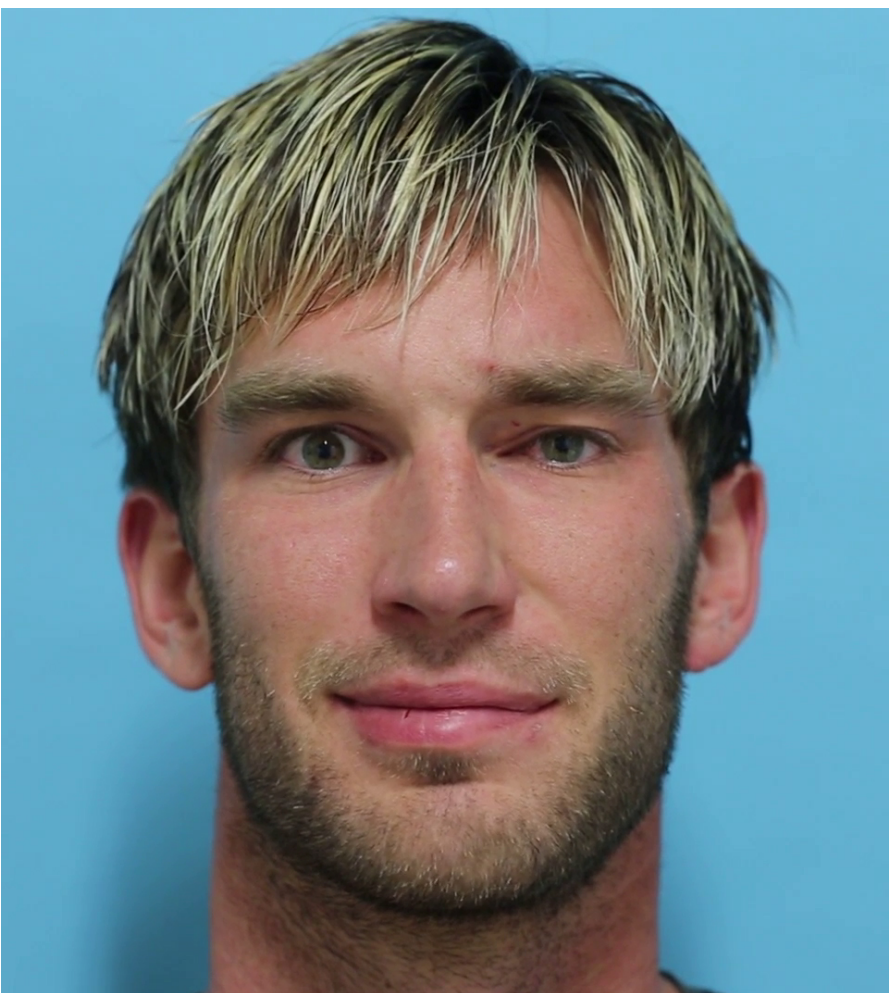

Figure 4. Reconstruction of the patient's smile after reconstructive surgery with symmetric elevation of the corners of the mouth, nasolabial fold creasing and mild synkinesis of the left orbicularis oculi muscle.

surgery $[3,4]$. In this case, nerve coaptation was not a viable option because of the extent of the nerve gap created by the laceration and the initially unlocated proximal nerve stump. The typical reconstructive approach in this case would have been a cross-facial nerve grafting to provide innervation from the contralateral facial nerve or the ipsilateral extra-facial nerve transfer to a free muscle graft [5-7]. In contrast to these methods, we restored the physiological muscle innervation by direct fascicular nerve repair of the proximal and distal facial nerve stumps [8-10]. Although other authors have reported on the fascicular structure of the facial nerve [11,12], Meissl's contribution is unique as it describes the method of correlating the fascicles of the nerve stem with target muscles. However, his description of the facial nerve intraneural topography is only a rough outline of the mimic muscle innervation pattern. Hence the procedure of topographic facial nerve transplantation carries the risk of mass movements, aberrant innervations and synkineses. Although these risks may be manageable with additional corrective interventions, further preclinical studies are necessary to refine and improve the knowledge of intraneural topography of the facial nerve.

\section{CONCLUSION}

This is the first clinical report that describes the application of Meissl's findings on the intraneural topography of the extracranial facial nerve. We were able to successfully reconstruct a facial nerve stump at the stylomastoid foramen according to the topographic pattern as proposed by him. The clinical out- 
comes were excellent as was evident in the follow-up examination after four years of surgery. However, current knowledge on the topography of the facial nerve is still coarse and its clinical use restricted to seldom events. Therefore, we plan further preclinical research to reinforce Meissl's findings and refine the topography of the fascicular architecture of the facial nerve.

\section{ARTICLE INFORMATION}

*Correspondence: Chieh-Han John Tzou, MD, PhD. Gumpendorfer Strasse 10-12/ Top 14, 1060 Vienna, Austria. Email: science@tzoumedical.com

Received: Sept. 03, 2020; Accepted: Nov. 20, 2020; Published:Jan. 23, 2021

DOI: 10.24983/scitemed.imj.2021.00139

Ethics Approval and Consent to Participate: The study is in accordance with the ethical standards of the 1964 Helsinki declaration and its later amendments or comparable ethical standards.

Informed Consent: Informed consent was obtained from the patient for publication of this Case report and any accompanying images.

Funding: The study did not receive any specific grant from funding agencies in the public, commercial, or not-for-profit sectors.

Conflict of Interest: The authors report no financial or other conflict of interest relevant to this article, which is the intellectual property of the authors.

Copyright $\odot 2021$ The Authors. This is an open-access article distributed under the terms of the Creative Commons Attribution 4.0 International License (CC-BY).

\section{REFERENCES}

1. G Meissl. Die intraneurale Topographie des extrakraniellen Nervus facialis. Acta Chir Austr 1979, Suppl 28:1-17.

2. BG Ross, G Fradet, JM Nedzelski. Development of a sensitive clinical facial grading system. Otolaryngol Head Neck Surg 1996;114(3):380386.

3. $\mathrm{H}$ Millesi. Factors affecting the outcome of peripheral nerve surgery. Microsurgery 2006;26(4):295-302.

4. Brushart TM. Nerve Repair. New York, NY: Oxford University Press, Inc; 2011

5. M Frey, M Michaelidou, C-H Tzou, A Hold, I Pona, E Placheta. Proven and innovative operative techniques for reanimation of the paralyzed face. Handchir Mikrochir Plast Chir 2010;42(2):81-89.

6. SM Rozen. Facial reanimation: basic surgical tools and creation of an effective toolbox for treating patients with facial paralysis: part B. nerve transfer combined with cross-facial nerve grafting in the acute facial palsy patient. Plast Reconstr Surg 2017;139(3):725-727.

7. Ritvik P Mehta. Surgical treatment of facial paralysis. Clin Exp Otorhinolaryngol 2009;2(1):1-5.

8. Natalie A Brill, Dustin J Tyler. Quantification of human upper extremity nerves and fascicular anatomy. Muscle Nerve 2017;56(3):463-471.

9. H Millesi, G Meissl, A Berger. The interfascicular nerve-grafting of the median and ulnar nerves. J Bone Joint Surg Am 1972;54(4):727-750.

10. S Sunderland. The intraneural topography of the radial, median and ulnar nerves. Brain 1945;68:243-299.

11. Jorge $O$ Güerrissi, Maximiliano F Gil Miranda. Intraneural topography of the extratemporal facial nerve: microsurgical nerve reconstruction. J Craniofac Surg 2007;18(3):578-585.

12. Guillaume Captier, François Canovas, François Bonnel, François Seignarbieux. Organization and microscopic anatomy of the adult human facial nerve: anatomical and histological basis for surgery. Plast Reconstr Surg 2005;115(6):1457-1465. 